\title{
A null mutation at the c-jun locus causes embryonic lethality and retarded cell growth in culture
}

\author{
Randall S. Johnson, ${ }^{1,2,4}$ Barbara van Lingen, ${ }^{3}$ Virginia E. Papaioannou, ${ }^{3}$ and Bruce M. Spiegelman ${ }^{1,2,5}$ \\ ${ }^{1}$ Dana-Farber Cancer Institute, ${ }^{2}$ Department of Biological Chemistry and Molecular Pharmacology, Harvard Medical School \\ 02115 USA; ${ }^{3}$ Department of Pathology, Tufts University, School of Medicine and Veterinary Medicine 02111 USA
}

The AP-1 transcription factors are considered immediate-early response genes and are thought to be involved in a wide range of transcriptional regulatory processes linked to cellular proliferation and differentiation. To study one of the key members of this family, the proto-oncogene c-jun, we have used homologous recombination-mediated gene targeting to produce mice with a c-jun null mutation. c-jun null embryos die at mid-gestation, with an average time of death of $\mathbf{1 2 . 5}$ days postcoitus. Homozygous mutant embryos are indistinguishable from wild-type littermates both grossly and histologically until the time of death. However, primary fibroblasts derived from live heterozygous and homozygous mutant embryos show greatly reduced growth rates in culture. The subnormal mitogenic response of these cells cannot be overcome by the addition of a number of purified mitogens. These studies indicate that although c-jun is not required for cellular proliferation and differentiation up to mid-gestation, it is required for survival past that stage as well as for the mitogenic response of embryonic fibroblasts in culture.

[Key Words: AP-1 transcription factor; c-jun locus; embryonic lethality; cell growth]

Received April 22, 1993; revised version accepted May 13, 1993.

The c-jun proto-oncogene is the cellular homolog of the oncogene carried by the defective avian sarcoma 17 retrovirus (Maki et al. 1987). It belongs to a family of related genes that includes junD and jun $B$ (for review, see Vogt and Bos 1990). The proteins encoded by these genes function as transcription factors by forming homodimers or heterodimers with one another or with proteins encoded by the c-fos-related genes; these protein complexes bind consensus DNA sequences termed activation protein-1 (AP-1) sites (for review, see Angel and Karin 1991). The AP-1 sequences have also been characterized as TPA (12O-tetradecanoyl phorbol 13-acetate) response elements, or TRE. Dimer formation in the Jun family of proteins is mediated by a leucine zipper, a basic region found in a large number of transcription factors, consisting of a heptad repeat of leucines in a coiled coil motif. These leucine side chains mediate hydrophobic interactions required for dimerization and DNA binding of the c-junand c-fos-related gene products (Kouzarides and Ziff 1989; Nakabeppu and Nathans 1989).

Studies of c-jun expression indicate that it belongs to the immediate-early class of genes, which are rapidly and transiently induced in response to mitogenic stimuli in

\footnotetext{
${ }^{4}$ Present address: Hormone Research Institute, Department of Biochemistry and Biophysics, University of California at San Francisco, San Francisco, California 94143-0534 USA.

${ }^{5}$ Corresponding author.
}

quiescent cells (Curran and Franza 1988). Studies of c-jun expression during embryonic development indicate that it is expressed nearly ubiquitously, albeit with particular prominence in tissues containing regions of rapidly dividing cells (Wilkinson et al. 1989). The ability of Fos and Jun and related AP-1 factors to form heterodimers with one another with varying degrees of affinity has led to a proposed matrix model of AP-1 activation of gene transcription. This would allow the various members of the AP-1 transcription factor family to regulate cellular responses to stimuli via differential rates of heterodimer formation, DNA binding, and transcriptional activation, dependent on the specific Fos-Jun moieties and AP-1-binding sites involved (Ryseck and Bravo 1991). This model suggests that deficiencies in particular AP-1 family members might have very specific effects. Supporting evidence for this model comes from recent studies demonstrating that a c-fos null mutation leads to a number of tissue-specific deficits of function; some of the most striking of these deficits occur in the bone and central nervous system (CNS) (Johnson et al. 1992; Wang et al. 1992).

Studies of the expression of AP-1 factors following growth factor stimulation of quiescent cells have suggested their involvement in the initial events of mitogenesis. Because they are transcription factors, they may function as a transcriptional triggering mechanism, setting off a cascade of events that eventually lead to cell 
division. A number of studies have attempted to connect AP-1 factor function with cell cycling and mitogenic response. A recent study by Kovary and Bravo, which supports this theory, showed that NIH-3T3 cells microinjected with antibodies that specifically bound c-jun-encoded protein were almost completely prevented from progressing through mitosis (Kovary and Bravo 1991). Other studies have linked c-jun expression to cellular processes as diverse as kindling during epileptic seizures, tumor progression in a transgenic fibrosarcoma model, and the differentiation of teratocarcinoma cell lines ( $\mathrm{Si}$ monato et al. 1991; Bossy-Wetzel et al. 1992; Hilberg and Wagner 1992). In contrast, however, one recent study of targeted embryonic stem (ES) cells found no effects on cell growth or differentiation in vitro in the absence of a functional c-jun gene (Hilberg and Wagner 1992). Thus, it appears that c-jun may fulfill different roles in different cell and tissue types.

To study this question further, we have undertaken gene targeting in ES cells to introduce a null mutation in the c-jun gene in mice. We report here that a null mutation in the c-jun proto-oncogene is lethal at mid-gestation, causing death at a median time of 11-12 days postcoitus (p.c.). Embryos were generally at an appropriate size and state of development at the time of loss of viability. Primary embryonic fibroblasts (EFs) isolated from heterozygous embryos at day 11.5 p.c. exhibit greatly reduced growth rates in culture, and cells homozygous for the null mutation exhibit virtually no growth following isolation from otherwise viable embryos. These results illustrate the requirement for c-jun in murine development and identify one cell type that is strongly affected by this mutation.

\section{Results}

\section{Cloning and targeting of the murine c-jun gene}

Using a mouse c-jun cDNA fragment as a probe, we screened a $\lambda$ phage genomic library constructed from the PCC4 embryonal carcinoma cell line, which was in turn derived from the 129 inbred mouse strain. After cloning and restriction mapping a phage clone that contained the entire coding region of the c-jun gene, a 5-kb fragment was subcloned for use as a targeting vector (Fig. 1). This cloned sequence extended from a $5^{\prime} \mathrm{BamHI}$ site at nucleotide +140 to a $3^{\prime} X b a I$ site $\sim 2 \mathrm{~kb}$ downstream of the $3^{\prime}$ end of the coding region. We then used a promoterless G418-resistance cassette derived from the pMC1neopA plasmid containing the entire neo ${ }^{r}$-coding sequence and its polyadenylation sequence as an insertion into the $5^{\prime}$ untranslated leader sequence of the c-jun gene. A frameshift mutation was created in the coding region of the c-jun gene at the AatII restriction site at codon 65 (Asp) through cutting, mung bean nuclease treatment, and ligation of the resulting blunt end.

Five homologous recombination-mediated targeting events were observed out of 42 G418-resistant ES cell clones screened by Southern blot. One clone was selected for injection into $\mathrm{C} 57 \mathrm{BL} / 6 \mathrm{~J}$ blastocysts to obtain chimeric mice. Of 25 offspring born, 4 males and 1 hermaphrodite were overt chimeras ranging from 50-90\% chimerism as judged by coat color. Two of the three fertile males transmitted the ES cell genotype to their progeny. One of these males, which transmitted the ES cell genotype to $96 \%$ of its offspring, was mated to C57BL/6) females to produce $F_{1}$ heterozygotes, and to $129 / \mathrm{Sv} / \mathrm{Ev}$ females to produce inbred mice bearing the c-jun mutation. Heterozygous mice from each of these crosses were mated inter se to provide $F_{2}$ or inbred embryos of all three genotypes. Southern blots of EF cells derived from individual embryos from an $F_{1}$ cross can be seen in Figure 2. They demonstrate the presence of all three genotypes expected within an intercross litter. The presence of the mutation that was originally created in the targeting vector in the genomic DNA of the mice was confirmed by the loss of the AatII restriction site at codon 65. (data not shown)

\section{RNA analysis shows no wild-type c-jun $m R N A$}

Primary embryonic fibroblasts (EFs) were isolated from
Figure 1. Genomic region at the c-jun locus and the c-jun targeting vector. The solid region is c-jun leader sequence, the open region is coding sequence, and the stippled region is c-jun-coding sequence downstream of the frameshift mutation at the AatII site.

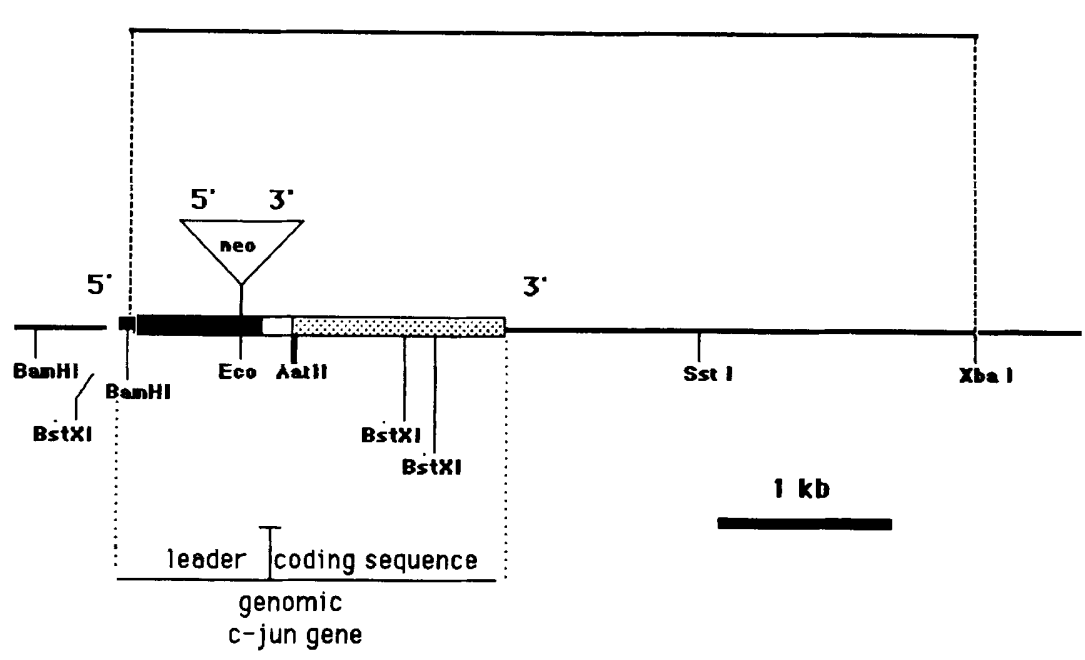




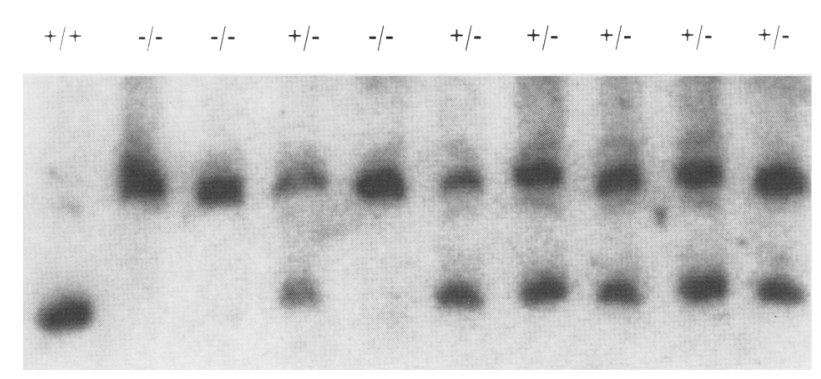

Figure 2. Genomic DNA from embryos indicates the presence of all three expected genotypes. Southern digest is of fetal tissue DNA recovered from $F_{1}$ intercross-derived EF cells and digested with BstXI. The blot was probed with a c-jun cDNA probe. All three predicted genotypes are present in this litter. The upper (and mutant) allele is $2.7 \mathrm{~kb}$, and the lower band (wild-type allele) is $1.9 \mathrm{~kb}$.

individual inbred, 11.5-day p.c. wild-type and mutant embryos. EF cells were allowed to grow to confluence in Dulbecco's modified Eagle medium (DMEM) plus 10\% fetal calf serum (FCS) and were then placed in DMEM plus $0.5 \%$ FCS for $96 \mathrm{hr}$. They were then washed once in $1 \times$ PBS and placed in DMEM plus $20 \%$ FCS supplemented with $100 \mathrm{ng} / \mathrm{ml}$ of TPA for $1 \mathrm{hr}$ before isolation of RNA. The stimulated wild-type EF cells exhibited high levels of endogenous c-jun mRNA expression $\mid 2.7$ and $3.2 \mathrm{~kb}$ ). The expression levels of the wild-type message in heterozygous cells was significantly reduced compared with wild-type $(\sim 50 \%)$, and homozygous mutant cells expressed no detectable wild-type c-jun message (Fig. 3A). Thus, a null mutation appears to have been introduced into the c-jun gene. Total RNA from these cells was also examined for $j u n B, j u n D$, and $\mathrm{c}$-fos gene expression: No significant change in the stimulated expression levels of those genes was detected (Fig. 3B-D).

\section{Mice homozygous for the c-jun null mutation die at mid-gestation}

Among 101 intercross progeny born from heterozygous parents, no homozygous mutant animals were found. This led us to examine the morphology and genotype of intercross and inbred fetuses recovered in utero at various time points p.c. Because no differences were observed between the two strains, these data have been combined. As shown in Table 1 and Figure 4, the majority $(12 / 14)$ of homozygous null fetuses that were recovered at the earliest time point (11.5 days p.c.) appeared viable, with beating hearts and normal morphology. At 12.5 days p.c., $6 / 9$ null mutants were viable, but by 13.5 days p.c. only half $(9 / 18)$ were alive and there was an increase in the proportion of moles and resorptions that could not be genotyped. After 13.5 days p.c., all but one fetus typed as homozygous for the null c-jun allele were dead, and there was a large number of moles and resorptions found.

Among the viable embryos, there was no stage at which the mutants or heterozygotes could be distin- guished from wild type by size, gross morphology, or developmental stage. Normal heartbeat and blood circulation were observed, and the fetuses were not obviously anemic. Null embryos that were dead at the time of recovery generally had normal-sized placentas and developmental features that were consistent with development to a median embryonic age of 11-12 days (Fig. 5). These data indicate that the majority of homozygous null mutant fetuses die between 11.5 and 13.5 days p.c., but with a wide range in the time of death. Histological examination of viable embryos, as well as their placentas and yolk sacs, at $11.5,12.5$, and 13.5 days p.c. revealed no readily detectable differences in development or morphology between the c-jun null fetuses and their heterozygous and homozygous littermates. All organ rudiments showed age-appropriate structure and histological appearance, including tissues known to express c-jun at high levels during development, such as skeletal muscle, developing cartilage and the CNS and peripheral nervous systems (PNS) (Fig. 6). Liver hematopoiesis appeared to be progressing normally (Fig. $6 \mathrm{E}, \mathrm{F}$ ).

\section{Retarded growth of cultured primary EFs heterozygous and homozygous for the c-jun null mutation}

Primary EFs were derived from the progeny of inbred 129 mice heterozygous for the c-jun mutation. All cells were harvested from viable embryos with visibly beating hearts at 11.5 days p.c. The EF lines were passed between one and three times from the embryo to identical initial cell densities. Plating efficiency was measured as the number of adherent, viable cells attached at $6 \mathrm{hr}$ after passage versus the initial number plated. Cells of all three genotypes had plating efficiencies of $\sim 30 \%$ by this assay during the first three passages. As can be seen in Figure 7, the growth of EF cell lines in DMEM plus $10 \%$ FCS is severely reduced in the cells from homozygous c-jun null mutant embryos. In addition, there is a
A. C-JUN

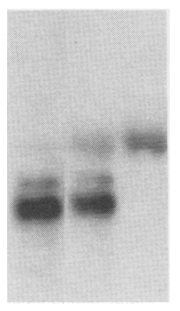

$+1++1--1$
B. JUNB

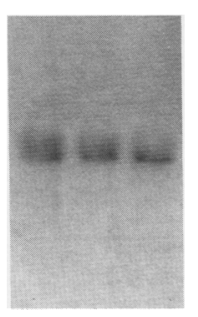

$+1++/--1-$
C. JUND

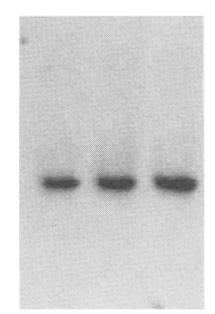

$+1++/--1-$
D. C-FOS

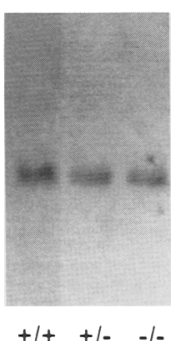

Figure 3. Loss of wild-type c-jun RNA in cells from mutant embryos. Northern blot of $10 \mu \mathrm{g}$ of total RNA recovered from quiescent EF cells stimulated with $20 \%$ FCS and $100 \mathrm{ng} / \mathrm{ml}$ of TPA for $1 \mathrm{hr}$ before RNA isolation. Blots were probed with random-primed ${ }^{32} \mathrm{P}$-labeled c-jun $(A), \operatorname{jun} B(B), \operatorname{jun} D(C)$, or c-fos (D) cDNA probes. The normal c-iun transcripts are 2.7 and 3.2 $\mathrm{kb}$. The larger transcript $(4 \mathrm{~kb})$ visible in the RNA derived from the heterozygous and homozygous EF cells is presumably the product of the c-iun gene containing the neo cassette and frameshift mutation. 
Table 1. Genotypes and viability of embryos recovered between 11.5 and 18.5 days p.c. from matings of mice heterozygous for the c-jun mutation

\begin{tabular}{|c|c|c|c|c|c|c|}
\hline \multirow[b]{2}{*}{ Days p.c. } & \multirow{2}{*}{$\begin{array}{l}\text { Number } \\
\text { of litters }\end{array}$} & \multirow{2}{*}{$\begin{array}{l}\text { Total } \\
\text { number } \\
\text { of implants }\end{array}$} & \multicolumn{3}{|c|}{$\begin{array}{c}\text { Number of each c-jun genotype } \\
\text { (number dead) }\end{array}$} & \multirow{2}{*}{$\begin{array}{l}\text { Number of untyped } \\
\text { moles or resorptions } \\
\text { (\% of total) }\end{array}$} \\
\hline & & & $+1+$ & $+1-$ & $-1-$ & \\
\hline 11.5 & 8 & $60^{c}$ & 5 & 38 & $14(2)$ & $2|3|$ \\
\hline 12.5 & 4 & 37 & 11 & $15(1)$ & $9(3)$ & $2(5)$ \\
\hline 13.5 & 9 & 87 & 15 & $37(1)$ & $18(9)$ & $7|8|$ \\
\hline 14.5 & 5 & $49^{c}$ & 9 & 25 & $8(7)$ & $6(12)$ \\
\hline 15.5 & 3 & 29 & 8 & 15 & $2(2)$ & $4(14)$ \\
\hline $17.5-18.5$ & 5 & 34 & 10 & $18(2)$ & $1(1)$ & $5(15)$ \\
\hline
\end{tabular}

a + | Wild type; $(-)$ the null allele for c-jun.

bNA too degraded for analysis.

'Including one normal, viable embryo not typed for technical reasons.

smaller but significant reduction in cell growth in the cells heterozygous for the mutation.

It is possible that the poor growth of the mutant cells reflects a selective inability to respond to certain growth factors. An implied corollary is that these cells might respond normally to certain mitogens not found in sufficient quantity in FCS. To determine whether specific mitogenic factors had differing effects on the c-jun mutant EF cells, growth of the cells in low serum with added purified growth factors was also examined. Cells were grown in DMEM plus $0.5 \%$ human platelet poor plasma [which has very low levels of the mitogen platelet-derived growth factor (PDGF)|; growth rates indicate that there was little if any response in the homozygous null mutant EF cells (see Fig. 8) to the mitogens PDGF, transforming growth factor- $\alpha$ (TGF- $\alpha$, and basic fibroblast growth factor (FGF) or TPA, or TPA and insulin in combination with TGF- $\alpha$, and that there was a retarded response to the same factors in heterozygous cell lines.

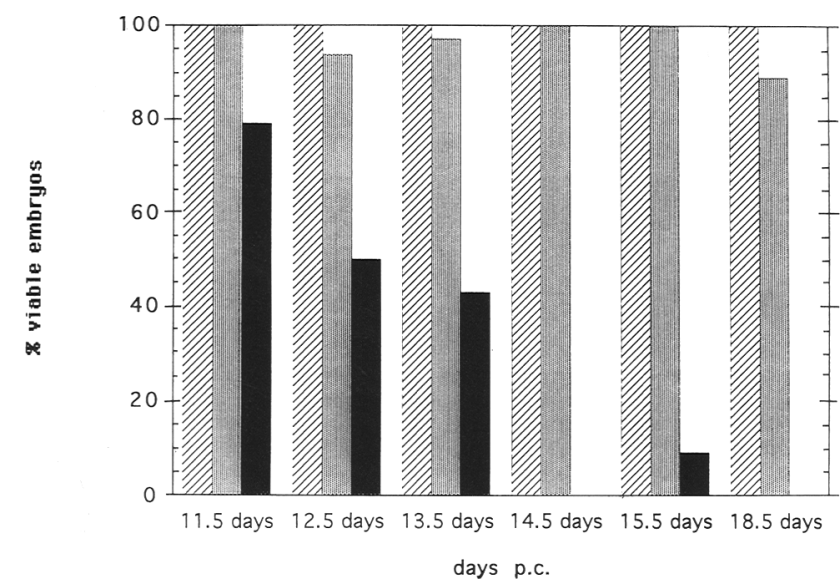

Figure 4. Viability of c-jun null mutants in utero. Graph depicting the percentage of viable embryos of each genotype recovered from heterozygous matings analyzed at various time points p.c. (Hatched bar) Wild type; (stippled bar) heterozygote; (solid bar) null. Birth occurs at $\sim 19.5$ days p.c. All embryos were genotyped by PCR and/or Southern blot.
This indicates that a functional c-iun allele is required for the proliferative response of EF cells to these mitogens.

\section{Discussion}

Previous evidence suggested an important role for AP-1 factors in the control of cell growth because of their identity as proto-oncogenes, transcription factors, and as part of the immediate-early response to mitogens. Here, we describe two clear effects of a c-jun null mutation: a loss of viability at mid-gestation in homozygous null embryos, and a retardation in the growth of mutant primary EFs. These results demonstrate that c-jun is not required for the growth and differentiation of many tissues and organ rudiments until mid-gestation. Also demonstrated is a requirement for $\mathrm{c}$-jun for the growth of primary EFs in culture.

The widespread expression of c-jun during development in proliferating tissues and its high levels of expression in certain differentiating tissues, including

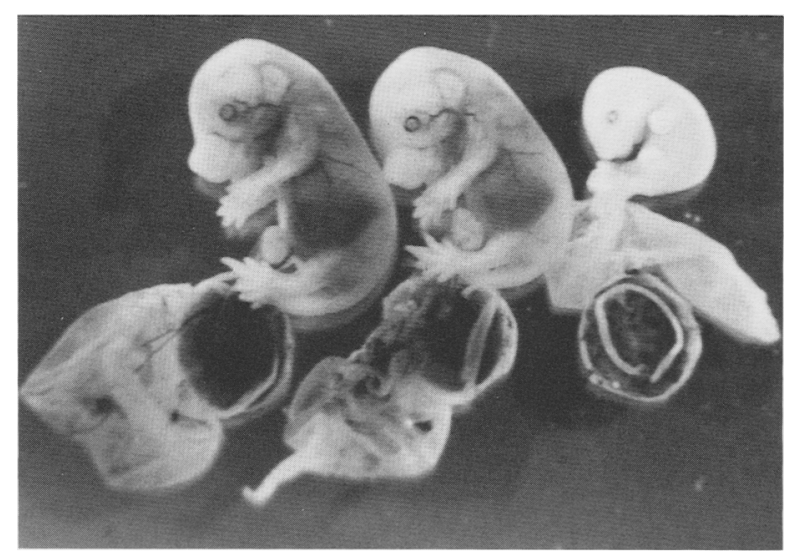

Figure 5. Dissected 15.5-day p.c. embryos and their placentae and yolk sacs. The viable embryos are wild type (middle) and heterozygous (left), whereas the dead, necrotic embryo (right) is homozygous for the c-iun allele. 
Embryonic lethality in c-jun mutant mice

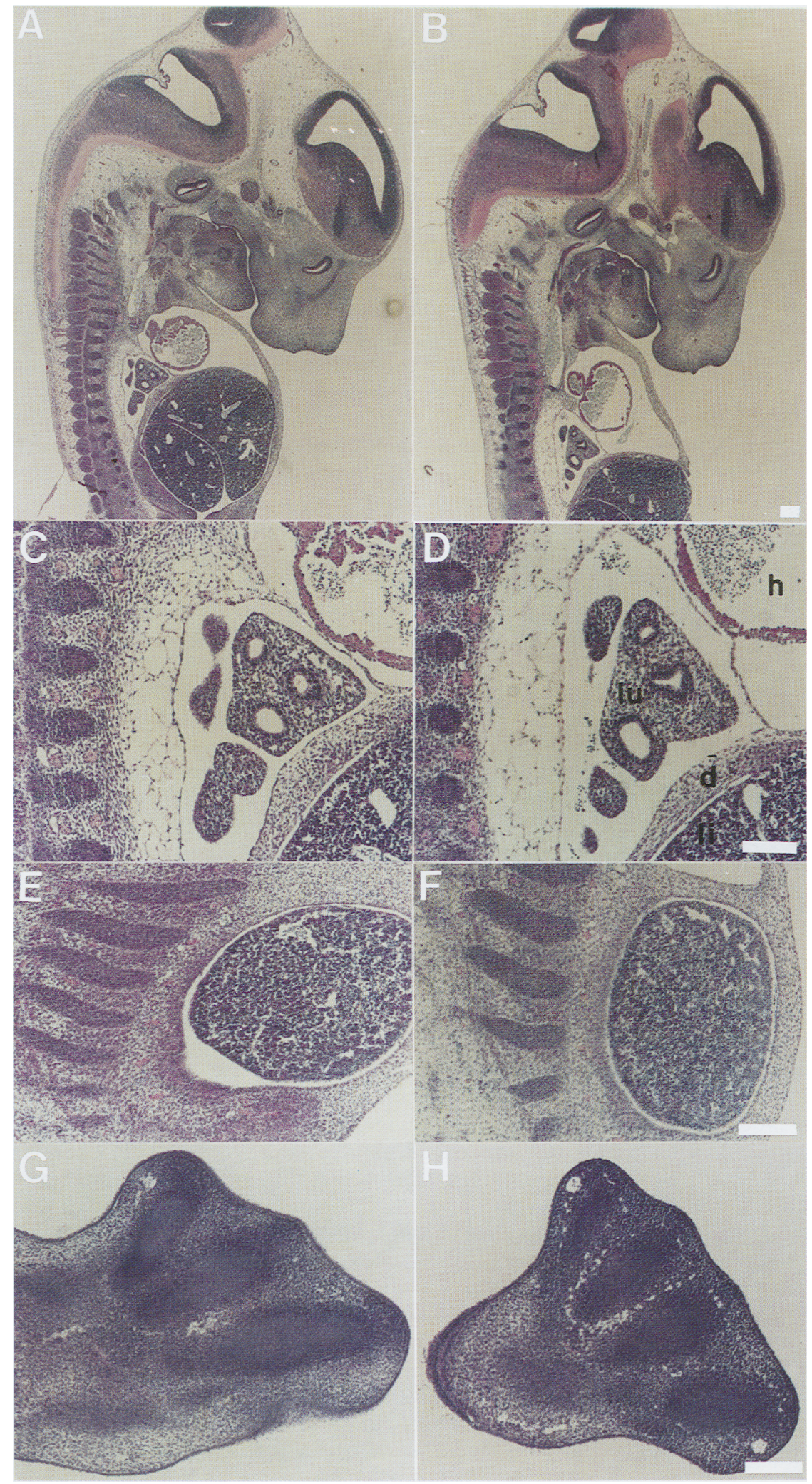

Figure 6. Histological comparison of wild-type $(A, C, E, G)$ and homozygous mutant c-jun $(B, D, F, H)$ littermates at $12.5(A-$ $F)$ and $13.5(G, H)$ days p.c., illustrating the similarity of development through midgestation. $C$ and $D$ are details of the sagittal sections of $A$ and $B$ showing lung (lu), diaphragm (d), heart (h), and liver (li). $E$ and $F$ show developing ribs and liver of the same embryos at a different level. $G$ and $H$ are sections of the hindlimbs of embryos 1 day older, showing precartilage condensation of the future digits. Bar, $200 \mu \mathrm{m}$. postmitotic neurons (Wilkinson et al. 1989; J.D. Gearhart, pers. comm.l, has led to the idea that it may be involved both in the proliferative response of early em- bryonic cells to growth factors and in the differentiation of specific embryonic cell types during organogenesis. An essential role for c-jun in the general regulation of 


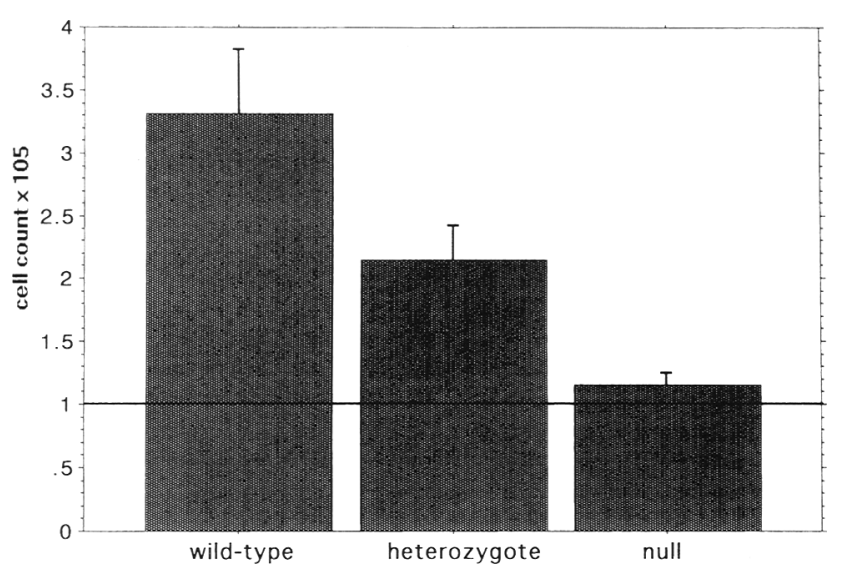

Figure 7. Reduced growth of mutant embryonic fibroblasts in culture. Mean cell counts $48 \mathrm{hr}$ after plating $10^{5}$ cells on 100mm plates. The solid horizontal line represents the initial number of cells plated. Growth was in $10 \%$ FCS, high-glucose DMEM supplemented with glutamine. Plating viability was determined for each line as described in Materials and methods; each line displayed approximately equivalent plating efficiencies. These counts represent values from cell lines derived from three different inbred litters and passaged once after isolation from the embryo at identical densities before passage for this experiment. Cells were then passaged onto duplicate plates, and the mean value for each duplicate was used to represent the cell counts from that cell line. The homozygous mutant value contains counts from six independent null EF lines, the heterozygous value contains data from eight independent heterozygous EF lines, and the wild-type data contain counts from six independent wild-type EF lines. Error bars represent 1 5.E. from the mean. All the differences in means are statistically significant, with the differences between wild type and null at $\mathrm{P}=0.002$, null and heterozygote at $\mathrm{P}=0.01$, and wild-type and heterozygote at $\mathrm{P}=0.05$.

growth-factor-responsive genes of the early embryo does not fit with our observation that mutant embryos develop normally to mid-gestation. The death of mutants at or shortly after mid-gestation could be the result of age-specific changes in the control of cell proliferation, such that c-jun becomes essential for proliferation after this time, or, alternatively, mutant death could result from a structural or functional defect in a cell type or tissue normally dependent either directly or indirectly on c-jun expression.

The death of embryos at mid-gestation is seen in a number of recessive mutations, both naturally occurring, for example, patch (Lyon and Searle 1990), and null mutations induced by gene targeting, for example, those in the c-myb, N-myc, and retinoblastoma genes (Mucenski et al. 1991; Charron et al. 1992; Clarke et al. 1992; Jacks et al. 1992; Lee et al. 1992; Stanton et al. 1992), indicating that a number of crucial developmental events occur during this period. No obvious developmental deficiencies are detectable in the homozygous c-jun mutant embryos before their deaths; all organ rudiments are present, and the circulatory and hematopoietic systems are functional. Viable embryos homozygous for the null mutation appear to have grossly normal growth and development of a wide range of cells and tissues, including those in which c-iun is highly expressed such as the perichondrial cells of the limb bud, skeletal muscle of the diaphragm, and the ventricular layer of the CNS (Wilkinson et al. 1989).

Data from studies of c-jun function in vitro suggest that other AP-1 family members could substitute for the absence of c-iun in forming dimeric complexes and binding DNA (Angel and Karin 1991), allowing normal development of many tissues. However, the embryonic lethal phenotype of null embryos indicates that there are some tissues in which overlapping expression or redundant function of the other AP-1 family members cannot compensate for the loss of c-jun.

The loss of embryonic viability, coupled with the grossly normal development of the c-jun null mutants, suggests a tissue-specific deficit in some essential embryonic function at mid-gestation. Our findings indicate a close relationship between c-jun expression and one cellular function, fibroblast growth in response to serum or mitogens. This is in keeping with considerable data generated by other studies of this cell type, which have shown that inhibition of expression or function of other AP-1 factors or c-jun specifically leads to an inhibition of proliferation (for review, see Angel and Karin 1991). Overexpression of c-jun also has strong effects on fibroblast growth and morphology, leading to anchorage-independent growth and conferring the ability to grow in reduced serum (Castellazi et al. 1991). There is also evidence for c-jun involvement in fibroblast growth control from animal models of transformed fibroblastic tumors, or fibrosarcomas; these include the original studies of the v-jun oncogene-containing avian retrovirus 17, which was isolated from a fibrosarcoma (Maki et al. 1987), as well as transgenic mouse models of v-jun overexpression, which develop fibrosarcomas and rhabdomyosarcomas exclusively despite expression directed at a wide range of tissues (Schuh et al. 1990). Yet another recently discovered connection between c-jun and fibroblast transformation comes from studies of transgenic mice bearing a genomically integrated bovine papilloma virus transgene (Bossy-Wetzel et al. 1992). These mice develop fibrosarcomas that undergo a well-defined progression to a terminally aggressive tumor type; this progression is marked by a dramatic increase in c-jun expression. These connections between c-jun and fibroblast growth control coincide well with our findings of a reduced mitogenic response to serum and growth factors in c-jun mutant primary EFs. These data, taken together with the well-defined immediate-early response of c-jun to growth factor stimulation and its role as a transcription factor, indicate that c-jun plays a crucial role in the initial response to mitogens of this cell type. Although our present data suggest a general defect in the growth of c-jun-deficient fibroblasts, it will be interesting to determine whether there are any mitogenic stimuli, including other transforming genes, which will enable normal cell growth. While it is possible that this defect is involved in the death of the embryos, it is also possible that other 


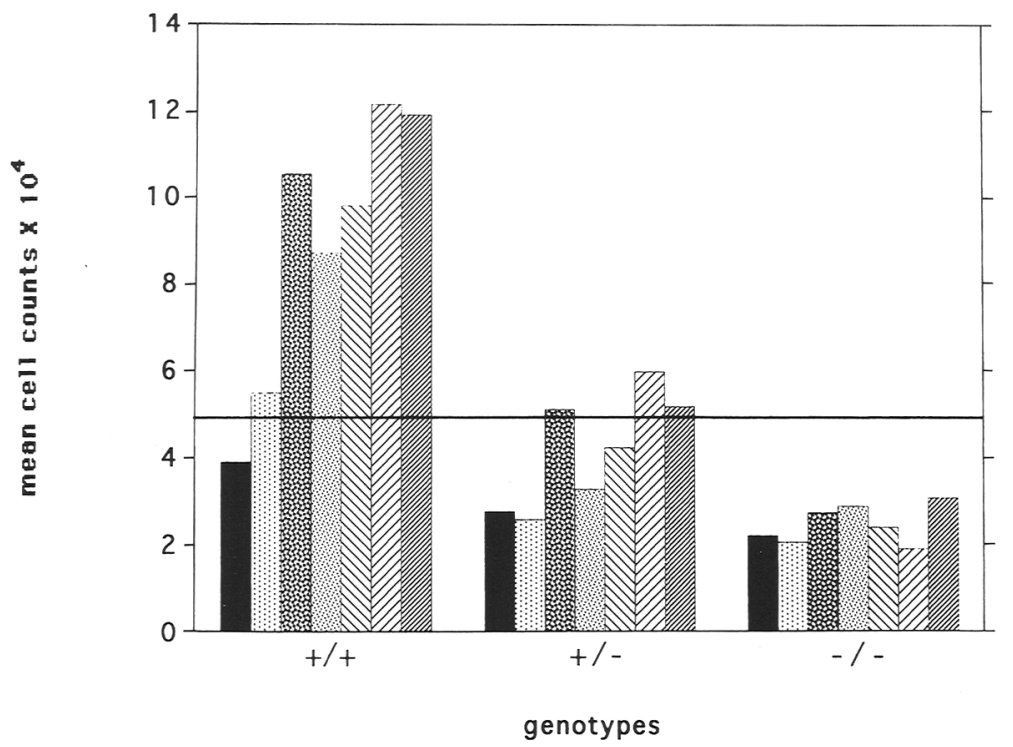

basic-fgf

tgf-alpha

tgf-alpha + tpa

genotypes
Wgf-alpha + tpa + insulin

Figure 8. Purified growth factors are unable to stimulate growth of c-jun mutant embryonic growth fibroblasts. Mean cell counts from $5 \times 10^{4}$ cells were plated in duplicate $10-\mathrm{cm}^{2}$ wells in DMEM plus $0.5 \%$ heat-inactivated human platelet-poor plasma for $72 \mathrm{hr}$, trypsinized, and electronically counted (day 0); they were then placed in DMEM plus $0.5 \%$ plasma alone or plus growth factor(s) for 96 additional hours. Day 4 counts are for DMEM and $0.5 \%$ plasma alone; or with either PDGF $(50 \mathrm{ng} / \mathrm{ml}$ added $) ;$ basic-FGF $(100 \mathrm{ng} / \mathrm{ml}$ added); TGF- $\alpha(100 \mathrm{ng} / \mathrm{ml}$ added $) ;$ or 100 $\mathrm{ng} / \mathrm{ml} \mathrm{TPA}$; or TPA and $5 \mu \mathrm{g} / \mathrm{ml}$ of insulin. EF cells were derived from individual embryos from a single litter and passaged once after isolation from the embryo in DMEM with $10 \%$ FCS at identical densities before passage for this experiment. Values represent means from duplicates under each condition for two independent wild-type, two independent heterozygous, and one homozygous mutant EF cell lines. cell types not yet analyzed will show similar derangements of function; these may ultimately be responsible for the loss of viability seen.

Targeting of the c-fos proto-oncogene demonstrates that Fos is required for the normal growth and/or function of a number of specific tissue types, such as the placenta and bone (Johnson et al. 1992; Wang et al. 1992). The phenotypes of the c-fos and c-jun null mutants taken together strengthen the hypothesis that the various AP-1 factors have both specific and differing roles, with a matrix of AP-1 activity allowing for the different transcriptional responses of different tissue types to many of the same or similar physiological stimuli. These mice should prove useful in further study of this model. In addition, the cells derived from these mice should enable a dissection of the role of c-jun in mitogenic signal transduction leading to fibroblast proliferation. Ultimately, the targeting and intercrossing of mice bearing mutant alleles of all of the cloned AP-1 factors should help to define the role of these genes in the control of signal transduction.

\section{Materials and methods \\ Cloning of the mouse $c$-jun gene}

A murine genomic DNA library from 129 strain PCC4 embryonal carcinoma cell line was obtained from Stratagene. Approximately $5 \times 10^{5}$ phage were screened using a random-primed murine cDNA c-jun probe obtained from the ATCC. Three ge nomic phage clones that hybridized to the probe were picked and plaque purified. They were then mapped by analysis of restriction digest, and one clone containing the entire c-jun-coding region was chosen from which to subclone a $5-\mathrm{kb}$ genomic fragment for targeting. The pMClneopA plasmid containing the $n e o^{\mathrm{r}}$-coding sequence, which was used as an insertion and a selectable marker in the targeting vector, was obtained from Stratagene.

\section{ES cell culture and gene targeting}

The c-jun gene targeting vector was linearized with NotI restriction enzyme and transfected by electroporation at $750 \mathrm{~V}, 15 \mu \mathrm{F}$, in $1 \times$ PBS as described (Johnson et al. 1989). The $129 /$ SvI-derived PJ5 ES cell line was cultured and transfected, and clones were selected as described (Johnson et al. 1992). Cells were used for electroporation at passage 6 from the blastocyst. G418-resistant clones were isolated, cultured for two passages, and assayed by Southern blot with a 500-bp SalI-EcoRI probe fragment derived from the $5^{\prime}$ sequence of the targeting vector; cells not used for DNA isolation were frozen. Clones positive for homologous recombination events were thawed, grown for one to three passages, and injected into 3.5-day p.c. C57BL/6J blastocysts to produce chimeras (Papaioannou and Johnson 1993).

\section{Animals}

Animals were housed in microisolator cages in a conventional animal facility that maintains viral antibody-free conditions. They were provided with standard laboratory chow and water ad lib. C57BL/6J mice for blastocyst injection and test breeding were obtained from the Jackson Laboratory. (129/SvJ $\times$ C57BL/ $6 \mathrm{~J}) F_{1}$ heterozygous offspring of chimeric males were mated inter se to produce all three genotypes used in this study. Inbred animals were derived by mating male chimeras to $129 / \mathrm{Sv} / \mathrm{Ev}$ females, genotyping the resultant progeny by Southern blot or $\mathrm{PCR}$, and intercrossing heterozygotes.

\section{Embryonic tissue isolation}

Primary EFs were derived from 11.5-day p.c. embryos as de- 
scribed (Robertson et al. 1986), with the exception that each embryo was treated individually and the tail was used for DNA isolation and genotyping by PCR. Cells were cultured in DMEM with $10 \%$ FCS for the first passage from the embryo and then treated as indicated for proliferation assays. Platelet-poor human plasma was obtained from Sigma and heat inactivated for $30 \mathrm{~min}$ at $56^{\circ} \mathrm{C}$ before use. Purified growth factors were obtained from Collaborative Research, Inc. Cells were counted at $1: 50$ dilutions in $1 \times$ Isoton by a Coulter counter. Cell viability was measured by vital dye (trypan blue) exclusion. For isolation of RNA after induction of immediate-early gene expression, cells were cultured in $0.5 \%$ FCS for $96 \mathrm{hr}$ and then placed in $20 \% \mathrm{FCS}$ and/or $100 \mathrm{ng} / \mathrm{ml}$ of TPA in DMEM for $1 \mathrm{hr}$.

\section{In utero recovery of fetuses and extraembryonic tissues}

Heterozygous animals were used to produce fetuses that were recovered for gross morphological, histological, and genotypic analysis. The number of litters and the number of fetuses examined at each age are listed in Table 1. Copulation plugs were checked daily, and the day of the plug was designated as 0.5 day p.c. Animals were sacrificed by cervical dislocation at various ages between 11.5 and 18.5 days p.c., and fetuses were dissected from the uteri and placed in PBS. Maternal tissue was removed, and yolk sac and amnion were dissected away from the placenta. Each fetus, still attached to yolk sac and amnion, was dissected away from its placenta by severing the umbilicus and then removed to a fresh PBS wash dish for individual treatment. The fetus was then severed from its extraembryonic tissues and transferred again to fresh PBS. As a precaution for avoiding DNA contamination of tail samples, all instruments were rinsed first in PBS and then in 10\% Clorox or hydrogen peroxide before handling of the fetuses. Tail samples were taken and lysed (lysis buffer: $50 \mathrm{~mm}$ Tris at $\mathrm{pH} 8,100 \mathrm{~mm}$ EDTA, $100 \mathrm{~mm}$ $\mathrm{NaCl}, 1 \% \mathrm{SDS}, 0.5 \mathrm{mg} / \mathrm{ml}$ of proteinase $\mathrm{K}$ ), and lysates were subsequently stored at $-20^{\circ} \mathrm{C}$ until analysis.

\section{Histological preparation}

Fetuses and extraembryonic tissue, including placentas, were fixed in $4 \%$ paraformaldehyde in $0.1 \mathrm{M}$ phosphate buffer, dehydrated, and stored in $70 \%$ ethanol until staining. They were then dehydrated, embedded in paraffin (Paraplast X-TRA), sectioned at $8 \mu \mathrm{m}$, and stained with hematoxylin and eosin. Sections from seven fetuses were examined in detail: one viable null embryo and one wild-type embryo at each age, 11.5, 12.5, and 13.5 days p.c.; and one heterozygous embryo at 12.5 days p.c.

\section{Hybridization and PCR}

Southern and Northern hybridization, and DNA and RNA isolation procedures were essentially as described previously (Johnson et al. 1989). PCR screening utilized specific probes for the neomycin sequence and the endogenous c-jun sequence. Combinations of these PCR reactions were used on some tail samples and all fetal tissue isolations to determine genotype. The sequences for the neomycin screening were $5^{\prime}$-TTCGGCTATGACTGGGCACAACAG-3' and 5'-GCTTCAGTGACAACGAGCACAGCCTGCGC-3'; the sequences for detection of the endogenous (unaltered) c-jun sequence were $5^{\prime}$-ACAGTTGTTGGAGGCC-3' and 5'-GCTAGCACACTCACGTTGGTAGG-3'. PCR was performed essentially as described (Saiki et al. 1988).

\section{Acknowledgments}

We acknowledge Kirk Donegan, John Anderson, and James Spencer for excellent technical assistance. We also thank Robert Distel, Jeremy Brown, Brett Satterberg, Lesley Michalowsky, Morgan Sheng, Michael Greenberg, Douglas Hanahan, David Murray, Peter Tontonoz, and the members of the Spiegelman and Papaioannou laboratories for helpful comments and suggestions, and John Gearhart for sharing unpublished results. This work was funded in part by grants HD27295 and HD24926 from the National Institutes of Health.

The publication costs of this article were defrayed in part by payment of page charges. This article must therefore be hereby marked "advertisement" in accordance with 18 USC section 1734 solely to indicate this fact.

\section{References}

Angel, P. and M. Karin. 1991. The role of Jun, Fos and the AP-1 complex in cell-proliferation and transformation. Biochim. Biophys. Acta. 1072: 129-157.

Bossy-Wetzel, E., R. Bravo, and D. Hanahan. 1992. Transcription factors jun $B$ and c-jun are selectively up-regulated and functionally implicated in fibrosarcoma development. Genes \& Dev. 6: 2340-2351.

Castellazi, M., G. Spyrou, N. LaVista, J.-P. Dangy, F. Piu, M. Yaniv, and G. Brun. 1991. Overexpression of c-jun, junB, or junD affects cell growth differently. Proc. Natl. Acad. Sci. 88: $8890-8894$.

Charron, J., B.A. Malynn, P. Fisher, V. Stewart, L. Jeannotte, S.P. Goff, E. J. Robertson, and F.W. Alt. 1992. Embryonic lethality in mice homozygous for a targeted disruption of the N-myc gene. Genes \& Dev. 6: 2248-2257.

Clarke, A.R., E.R. Maandag, M. van Roon, N.M. van der Lugt, M. van der Valk, M.L. Hooper, A. Berns, and H. te Riele. 1992. Requirement for a functional Rb-1 gene in murine development. Nature 359: 328-330.

Curran, T. and B.R.J. Franza. 1988. Fos and Jun: The AP-1 connection. Cell 55: 395-397.

Hilberg, F. and E.F. Wagner. 1992. Embryonic stem (ES) cells lacking functional c-jun: Consequences for growth and differentiation, AP-1 activity and tumorigenicity. Oncogene 7: 2371-2380.

Jacks, T., A. Fazeli, E.M. Schmitt, R.T. Bronson, M.A. Goodell, and R.A. Weinberg. 1992. Effects of an RB mutation in the mouse. Nature 359: 295-300.

Johnson, R.S., M. Sheng, M.E. Greenberg, R.D. Kolodner, V.E. Papaioannou, and B.M. Spiegelman. 1989. Targeting of nonexpressed genes in embryonic stem cells via homologous recombination. Science 245: 1234-1236.

Johnson, R.S., B.M. Spiegelman, and V.E. Papaioannou. 1992. Pleiotropic effects of a null mutation in the c-fos proto-oncogene. Cell 71: 577-586.

Kouzarides, T. and E. Ziff. 1989. Leucine zippers of fos, jun and GCN4 dictate dimerization specificity and thereby control DNA binding. Nature 340: 568-571.

Kovary, K. and R. Bravo. 1991. The jun and fos protein families are both required for cell cycle progression in fibroblasts. Mol. Cell. Biol. 11: 4466-4472.

Lee, E.Y., C.Y. Chang, N. Hu, Y.C. Wang, C.C. Lai, K. Herrup, W.H. Lee, and A. Bradley. 1992. Mice deficient for $\mathrm{Rb}$ are nonviable and show defects in neurogenesis and haematopoiesis. Nature 359: 288-294.

Lyon, M.F. and A.G. Searle. 1990. Genetic variants and strains of the laboratory mouse. Oxford University Press, Oxford, UK. 
Maki, Y., T.J. Bos, C. Davis, M. Starbuck, and P.K. Vogt. 1987. Avian sarcoma virus 17 carries the jun oncogene. Proc. Natl. Acad. Sci. 84: 2848-2852.

Mucenski, M.L., K. McLain, A.B. Kier, S.H. Swerdlow, C.M. Schreiner, T.A. Miller, D.W. Pietryga, W.J. Scott, and S.S. Potter. 1991. A functional c-myb gene is required for normal murine fetal hepatic hematopoiesis. Cell 65: 677-689.

Nakabeppu, Y. and D. Nathans. 1989. The basic region of Fos mediates specific DNA binding. EMBO I. 8: 3833-3841.

Papaioannou, V.E. and R.S. Johnson. 1993. Production of chimeras and genetically defined offspring from targeted ES cells. In Gene targeting: A practical approach (ed. A. Joyner). IRL Press, Oxford, UK

Robertson, E.J. 1987. Embryo-derived stem cells. In Teratocarcinomas and embryonic stem cells (ed. E.). Robertson), IRL Press, Oxford, UK.

Ryseck, R.P. and R. Bravo. 1991. c-jun, JUN B, and JUN D differ in their binding affinities to AP-1 and CRE consensus sequences: Effect of FOS proteins. Oncogene 6: 533-542.

Saiki, R.K., D.H. Gelfand, S. Stoffel, S.J. Scharf, R. Higuchi, K.B. Mullis, and H.A. Ehrlich. 1988. Primer-directed enzymatic amplification of DNA with a thermostable DNA polymerase. Science 239: 487-491.

Schuh, A.C., S.J. Keating, F.S. Monteclaro, P.K. Vogt, and M.L. Breitman. 1990. Obligatory wounding requirement for tumorigenesis in v-jun transgenic mice. Nature 346: 756-760.

Simonato, M., D.A. Hosford, D.M. Labiner, C. Shin, H.H. Mansbach, and J.O. McNamara. 1991. Differential expression of immediate early genes in the hippocampus in the kindling model of epilepsy. Mol. Brain Res. 11: 115-124.

Stanton, B.R., A.S. Perkins, L. Tessarollo, D.A. Sassoon, and L.F. Parada. 1992. Loss of $\mathrm{N}-\mathrm{myc}$ function results in embryonic lethality and failure of the epithelial component of the embryo to develop. Genes \& Dev. 6: 2235-2247.

Vogt, P.K. and T.J. Bos. 1990. jun: Oncogene and transcription factor. Adv. Cancer Res. 55: 1-35.

Wang, Z.Q., C. Ovitt, A.E. Grigoriadis, U. Mohle-Steinlein, U. Ruther, and E.F. Wagner. 1992. Bone and haematopoietic defects in mice lacking c-fos. Nature 360: 741-745.

Wilkinson, D.G., S. Bhatt, R.-P. Ryseck, and R. Bravo. 1989. Tissue-specific expression of c-jun and junB during organogenesis in the mouse. Development 106: 465-471. 


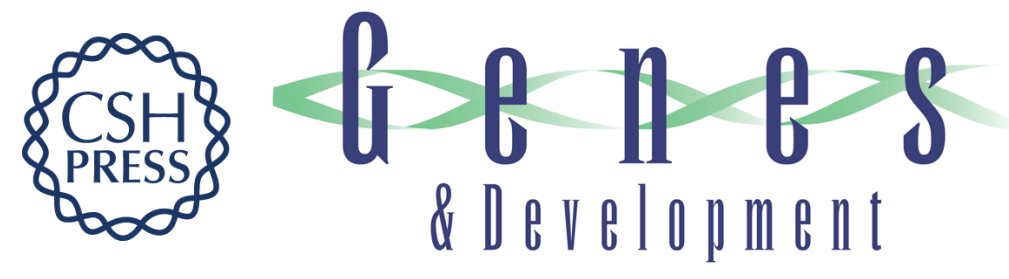

\section{A null mutation at the c-jun locus causes embryonic lethality and retarded cell growth in culture.}

R S Johnson, B van Lingen, V E Papaioannou, et al.

Genes Dev. 1993, 7:

Access the most recent version at doi:10.1101/gad.7.7b.1309

References This article cites 24 articles, 9 of which can be accessed free at:

http://genesdev.cshlp.org/content/7/7b/1309.full.html\#ref-list-1

License

Email Alerting

Receive free email alerts when new articles cite this article - sign up in the box at the

Service top right corner of the article or click here.

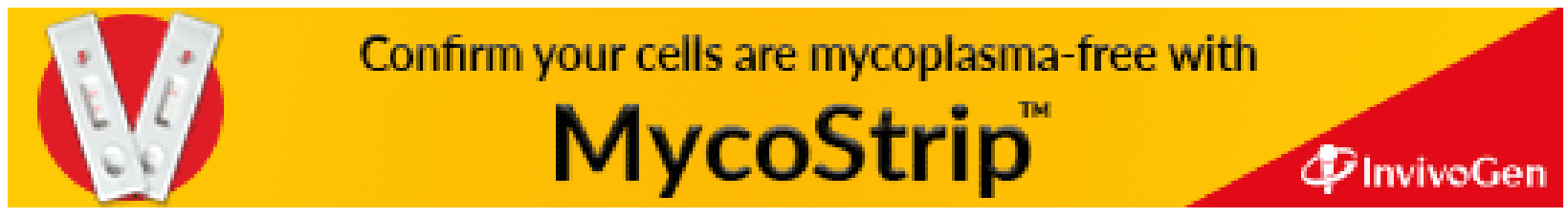

